\title{
Investigation of Clinical Manifestations in Korean Colorectal Cancer Patients
}

\author{
Hye Young Koo, Kyu Joo Park ${ }^{1}$, Jae Hwan $\mathrm{Oh}^{2}$, Sung Bum Kang ${ }^{3}$, Seong Taek $\mathrm{Oh}^{4}$, Woo Yong Lee \\ Department of Surgery, Samsung Medical Center, Sungkyunkwan University School of Medicine, Seoul; ${ }^{1}$ Department of Surgery, Seoul \\ National University College of Medicine, Seoul; ${ }^{2}$ Center for Colorectal Cancer, Research Institute and Hospital, National Cancer Center, \\ Goyang; ${ }^{3}$ Department of Surgery, Seoul National University Bundang Hospital, Seoul National University College of Medicine, Seongnam; \\ ${ }^{4}$ Department of Surgery, Seoul St. Mary's Hospital, The Catholic University of Korea College of Medicine, Seoul, Korea
}

Purpose: Early diagnostic work-up in patients with clinical symptoms of colorectal cancer (CRC) is important to achieve good treatment results. In this study, we investigated clinical symptoms when a diagnosis of CRC was made in patients who had a surgical resection, especially focusing on the relevance of constipation to CRC.

Methods: The clinical symptoms of 17,415 CRC patients who had curative surgery from January 2010 to December 2012 were collected from 24 training hospitals of surgery.

Results: The number of symptomatic patients before the diagnosis of CRC was 11,085 (63.7\%). Hematochezia or melena, abdominal pain, anemia, and constipation were more often found in female than male patients while bowel habit change was more common in male patients. Considering age, bowel habit change and hematochezia or melena were more common in patients younger than 60. Anemia and constipation, however, were more common in patients older than 60. According to the group classification based on age, patients older than 60 had experienced more constipation $(\mathrm{P}=0.049)$. Moreover, patients with constipation tended to have a more advanced disease status $(\mathrm{P}<0.001)$.

Conclusion: In patients who had surgery due to CRC, bleeding, abdominal pain, bowel habit change and constipation were the most frequent symptoms before diagnosis. Although whether or not constipation is a cause of CRC is unclear, it is one of the important clinical symptoms that presents in patients with CRC, and patients with a symptom of constipation tend to present with a more advanced CRC stage.

Keywords: Colorectal neoplasms; Clinical manifestations; Constipation

\section{INTRODUCTION}

Colorectal cancer (CRC) is the third most common malignancy in the world [1]. In Korea, CRC is also ranked in third place for cancer incidence, and the incidence rate of CRC in Korea is increasing [2]. Early detection of CRC is important in terms of can-

Received: August 23, 2013 - Accepted: August 28, 2013

Correspondence to: Woo Yong Lee, M.D.

Department of Surgery, Samsung Medical Center, Sungkyunkwan University School of Medicine, 81 Irwon-ro, Gangnam-gu, Seoul 135-710, Korea Tel: +82-2-3410-1668, Fax: +82-2-3410-6980,E-mail: Iwy555@skku.edu

(C) 2013 The Korean Society of Coloproctology

This is an open-access article distributed under the terms of the Creative Commons Attribution NonCommercial License (http://creativecommons.org/licenses/by-nc/3.0) which permits unrestricted noncommercial use, distribution, and reproduction in any medium, provided the original work is properly cited. cer-related mortality and good treatment results. It is easy to predict that CRC-patients with clinical symptoms have more advanced disease than asymptomatic patients. Because not everyone has an asymptomatic regular health check-up, clinical symptoms that may be indications of CRC may be helpful when people decide to go to the hospital. Such traditionally well-known clinical symptoms are bleeding (hematochezia or melena), loss of weight, abdominal pain, diarrhea, and constipation [3]. By observation, we found that patients with gastrointestinal bleeding, abdominal pain or anemia tended to visit the hospital more than the patients with constipation. In Korea, actually, many people tend to treat constipation with folk remedies. Thus, the risks of constipation, which might be a sign of CRC, may be overlooked, and some debate exists as to whether or not constipation should be considered a high risk factor for CRC. According to some reports, a positive 
association between constipation and an increased risk for colon cancer was found $[4,5]$. Other researchers, however, reported that long-term constipation did not raise the risk for colon and rectal cancers [6].

In this study, we investigated the clinical manifestations when a diagnosis of CRC was made in a patient who had a surgical resection. Also, we especially focused on the relevance of constipation to $\mathrm{CRC}$.

\section{METHODS}

In this study, the clinical symptoms of CRC patients who had curative surgery from January 2010 to December 2012 were ana-

Table 1. Patient characteristics $(n=17,415)$

\begin{tabular}{|c|c|}
\hline Characteristic & №. (\%) \\
\hline \multicolumn{2}{|l|}{ Age (yr) } \\
\hline Mean & 62.2 \\
\hline$<30$ & $135(0.8)$ \\
\hline $31-40$ & $617(3.5)$ \\
\hline $41-50$ & $2,073(11.9)$ \\
\hline $51-60$ & $4,640(26.7)$ \\
\hline $61-70$ & $5,283(30.4)$ \\
\hline $71-80$ & $3,885(22.3)$ \\
\hline$>80$ & $769(4.4)$ \\
\hline (Missing) & $13(0.01)$ \\
\hline \multicolumn{2}{|l|}{ Sex } \\
\hline Male & $10,522(60.4)$ \\
\hline Female & $6,859(39.4)$ \\
\hline (Missing) & $34(0.2)$ \\
\hline \multicolumn{2}{|l|}{ Stage } \\
\hline 0 & $250(1.4)$ \\
\hline I & $4,146(23.8)$ \\
\hline$\|$ & 4,647 (26.7) \\
\hline III & $5,922(34.0)$ \\
\hline IV & $2,006(11.5)$ \\
\hline (Missing) & $444(2.5)$ \\
\hline \multicolumn{2}{|l|}{ Symptom } \\
\hline No & 6,330 (36.3) \\
\hline Yes & $11,085(63.7)$ \\
\hline Bowel habit change & $3,348(19.2)$ \\
\hline Hematochezia or melena & $5,428(31.2)$ \\
\hline Abdominal pain & $3,761(21.6)$ \\
\hline Palpable mass & $350(2.0)$ \\
\hline Anemia & $946(5.4)$ \\
\hline Constipation & $2,609(15.0)$ \\
\hline Weight loss & $1,381(7.9)$ \\
\hline Abdominal distension & $502(2.9)$ \\
\hline
\end{tabular}

lyzed, retrospectively. Eight kinds of clinical symptoms were collected from 24 training hospitals of surgery (Appendix). Individual patients often experienced several symptoms before the diagnosis of CRC.

A total of 17,145 patients from 24 hospitals were enrolled in this study. Then, basic information on the patients, such as age, sex, TNM stage, and clinical symptoms, such as bowel habit change, hematochezia or melena, abdominal pain, palpable mass, anemia, constipation, weight loss, and abdominal distension, were collected based on medical records. All data in this study were analyzed using IBM SPSS ver. 18.0 (IBM Co., Armonk, NY, USA). For the statistical analysis, a chi-square test was used, and significance was set at $\mathrm{P}<0.05$.

\section{RESULTS}

The average age of the patients was 62.2 years old. The fifties (26.7\%) and the sixties (30.4\%) were the majority decades in the patients of this study. The proportion of male patients (60.4\%) was higher than that of female patients (39.4\%). Among the pa-

Table 2. Frequency of clinical symptoms according to sex (excluding missing data)

\begin{tabular}{|c|c|c|c|}
\hline & Male & Female & P-value \\
\hline Bowel habit change & & & 0.006 \\
\hline No & $8,425(80.1)$ & $5,608(81.8)$ & \\
\hline Yes & 2,097 (19.9) & $1,251(18.2)$ & \\
\hline Hematochezia or melena & & & $<0.001$ \\
\hline No & 7,397 (70.3) & $4,564(66.5)$ & \\
\hline Yes & $3,125(29.7)$ & 2,295 (33.5) & \\
\hline Abdominal pain & & & $<0.001$ \\
\hline No & $8,495(80.7)$ & $5,131(74.8)$ & \\
\hline Yes & 2,027 (19.3) & $1,728(25.2)$ & \\
\hline Palpable mass & & & 0.056 \\
\hline No & $10,328(98.2)$ & $6,704(97.7)$ & \\
\hline Yes & $194(1.8)$ & $155(2.3)$ & \\
\hline Anemia & & & $<0.001$ \\
\hline No & $10,041(95.4)$ & 6,395 (93.2) & \\
\hline Yes & $481(4.6)$ & $464(6.8)$ & \\
\hline Constipation & & & $<0.001$ \\
\hline No & $9,028(85.8)$ & $5,745(83.8)$ & \\
\hline Yes & $1,494(14.2)$ & $1,114(16.2)$ & \\
\hline Weight loss & & & 0.096 \\
\hline No & $9,657(91.8)$ & $6,343(92.5)$ & \\
\hline Yes & 865 (8.2) & $516(7.5)$ & \\
\hline Abdominal distension & & & 0.934 \\
\hline No & $10,219(97.1)$ & $6,660(97.1)$ & \\
\hline Yes & $303(2.9)$ & $199(2.9)$ & \\
\hline
\end{tabular}

Values are presented as number (\%). 
tients who were diagnosed with CRC, the number of symptomatic patients was $11,085(63.7 \%)$ (Table 1$)$.

Table 3. Frequency of clinical symptoms according to age (excluding missing data)

\begin{tabular}{|c|c|c|c|}
\hline & Age $\leq 60$ & Age $>60$ & P-value \\
\hline Bowel habit change & & & $<0.001$ \\
\hline No & $5,895(79.2)$ & 8,121 (81.8) & \\
\hline Yes & $1,545(20.8)$ & $1,802(18.2)$ & \\
\hline Hematochezia or melena & & & 0.002 \\
\hline No & $5,023(67.5)$ & 6,923 (69.8) & \\
\hline Yes & 2,417 (32.5) & $3,000(30.2)$ & \\
\hline Abdominal pain & & & 0.178 \\
\hline No & $5,797(77.9)$ & 7,816 (78.8) & \\
\hline Yes & $1,643(22.1)$ & $2,107(21.2)$ & \\
\hline Palpable mass & & & 0.207 \\
\hline No & $7,302(98.1)$ & $9,712(97.9)$ & \\
\hline Yes & $138(1.9)$ & $211(2.1)$ & \\
\hline Anemia & & & $<0.001$ \\
\hline No & $7,123(95.7)$ & $9,296(93.7)$ & \\
\hline Yes & 317 (4.3) & 627 (6.3) & \\
\hline Constipation & & & 0.025 \\
\hline No & $6,376(85.7)$ & 8,382 (84.5) & \\
\hline Yes & $1,064(14.3)$ & $1,541(15.5)$ & \\
\hline Weight loss & & & 0.07 \\
\hline No & 6,818 (91.6) & 9,168 (92.4) & \\
\hline Yes & $622(8.4)$ & 755 (7.6) & \\
\hline Abdominal distension & & & 0.191 \\
\hline No & $7,240(97.3)$ & $9,623(97.0)$ & \\
\hline Yes & $200(2.7)$ & $300(3.0)$ & \\
\hline
\end{tabular}

Values are presented as number (\%).

Table 6. Distribution of clinical symptoms in each TNM staging group

\begin{tabular}{|c|c|c|c|c|c|}
\hline \multirow{2}{*}{ Clinical symptoms } & \multicolumn{5}{|c|}{ Stage, $n(\%)$} \\
\hline & Stage $0(n=250)$ & Stage I $(n=4,146)$ & Stage II $(n=4,647)$ & Stage III $(n=5,922)$ & Stage IV $(n=2,006)$ \\
\hline No Symptom & $170(68.0)$ & $2,304(55.6)$ & $1,462(31.5)$ & $1,681(28.4)$ & $443(22.1)$ \\
\hline Bowel habit change & $26(32.5)$ & $578(31.4)$ & $976(30.6)$ & $1,297(30.6)$ & $456(29.4)$ \\
\hline Hematochezia or melena & $42(52.5)$ & $1,184(64.3)$ & $1,465(46.0)$ & $2,095(49.4)$ & $623(39.9)$ \\
\hline Palpable mass & $1(1.3)$ & $49(2.7)$ & $102(3.2)$ & $127(3.0)$ & $63(4.0)$ \\
\hline Anemia & 8 (10.0) & $124(6.7)$ & $328(10.3)$ & $350(8.3)$ & $133(8.5)$ \\
\hline Constipation & $21(26.3)$ & $322(17.5)$ & $671(21.1)$ & $1,106(26.1)$ & $460(29.4)$ \\
\hline Weight loss & $9(11.3)$ & $185(10.0)$ & $401(12.6)$ & $483(11.4)$ & $296(18.9)$ \\
\hline Abdominal distension & $1(1.3)$ & $38(2.1)$ & $146(4.6)$ & $193(4.6)$ & $117(7.5)$ \\
\hline
\end{tabular}

Some differences in the incidences of symptoms existed between male and female patients. Hematochezia or melena, abdominal pain, anemia and constipation were more often found in female than male patients while bowel habit change was more common in male patients (Table 2). Considering age, bowel habit change and hematochezia or melena were more common in patients younger than 60 . Anemia and constipation, however, were more common in the patients older than 60 (Table 3).

This study especially focused on constipation. Thus, diverse analyses of constipation and other parameters were performed. According to the group classification based on age, patients older than 60 years experienced more constipation $(\mathrm{P}=0.049)$, and patients with constipation tended to have more advanced disease status $(\mathrm{P}<0.001)$. In this study, we defined early stage as TNM 0 and I and advanced stage as TNM II, III, and IV (Tables 4, 5).

Further analyses between symptoms and stage were made (Table 6). The number of patients with constipation gradually increased from stage I to stage IV. Other symptoms, however, showed irregular patterns.

Table 4. Constipation rate according to age in symptomatic patients

\begin{tabular}{lccc}
\hline & \multicolumn{2}{c}{ Constipation, $\mathrm{n}(\%)$} & \multirow{2}{*}{ Total } \\
\cline { 2 - 3 } & No & Yes & \\
\hline Age $\leq 60$ & $3,641(77.4)$ & $1,064(22.6)$ & $4,705(100)$ \\
Age $>60$ & $4,825(75.8)$ & $1,542(24.2)$ & $6,367(100)$ \\
\hline
\end{tabular}

Table 5. Stage distribution according to constipation in symptomatic old-age patients

\begin{tabular}{lccc}
\hline \multirow{2}{*}{ Constipation } & \multicolumn{2}{c}{ Stage, $\mathrm{n}(\%)$} & \multirow{2}{*}{ Total } \\
\cline { 2 - 3 } & \multicolumn{1}{c}{ Early $(0, \mathrm{I})$} & Advanced (II, III, IV) & \\
\hline No & $867(18.2)$ & $3,884(81.8)$ & $4,751(100)$ \\
Yes & $196(12.9)$ & $1,329(87.1)$ & $1,525(100)$ \\
\hline
\end{tabular}




\section{DISCUSSION}

Diagnosis of CRC as early as possible is beneficial, and the incidence of early diagnosis can be improved by early screening of patients with specific cancer-related symptoms [7]. A report of Chen et al. [8] showed that early detection and removal of a colorectal adenoma in symptomatic patients might decrease the incidence of CRC.

CRC-related clinical symptoms are very diverse and include symptoms such as rectal bleeding, change in bowel habit (constipation or diarrhea), weight loss, abdominal pain, palpable mass and anemia [9]. In this study, we investigated symptoms that commonly present in patients with CRC in Korea. Alexiusdottir et al. [10] reported that right-sided tumors were associated with anemia and incidental diagnosis while left-sided tumors were associated with visible blood in stools and changes in bowel habits. Unfortunately, we did not analyze the association between tumor location and symptoms in this study. Alexiusdottir et al. [10] also found that visible blood in stool was significantly associated with lower TNM stage whereas abdominal pain, and general and acute symptoms were associated with higher TNM stage. In this study, we observed similar results in terms of hematochezia or melena, abdominal pain and constipation (Table 6). With these results, we can state that patients with rectal bleeding come into the hospital relatively early, so early diagnosis of CRC can be made. Abdominal pain, however, mostly appears at a late stage of CRC, so patients presenting with the symptom of pain are usually diagnosed with an advanced stage of CRC.

In terms of constipation, in October 2012, at the American College of Gastroenterology's 77th Annual Scientific Meeting in Las Vegas, a study, "Risk of developing CRC and benign neoplasm in patients with chronic constipation," investigated the prevalence and the incidence of CRC and benign neoplasms in a large-scale cohort. The study found that the risk of developing CRC was 1.78 times higher for chronic constipation patients. That study also found an increasing incidence of constipation with increasing tumor stage. Constipation might be related to preoperative bowel obstruction. Some studies have reported that preoperative bowel obstruction might be an indicator of worse long-term prognosis in CRC [11]. In an article recently reported by Seoul National University Bundang Hospital, the association between constipation severity and pathologic progression of rectal cancer was analyzed, and preoperative constipation severity was found to be associated with advanced pathologic stage and poor oncologic outcome in patients with rectal cancer [12].

In conclusion, through an investigation of the clinical symptoms in patients who had surgery due to CRC, we found that bleeding, abdominal pain, bowel habit change and constipation were the most frequent symptoms. CRC patients with bleeding tended to be in an early stage, and CRC patients with constipation tended to present with a more advanced stage. Although whether or not constipation is a cause of CRC is unclear, it is one of the important clinical symptoms that presents in patients with CRC. Thus, consultation with a colorectal specialist might be necessary when female patients over 60 years of age experience a symptom of constipation.

\section{CONFLICT OF INTEREST}

No potential conflict of interest relevant to this article was reported.

\section{REFERENCES}

1. Siegel R, Naishadham D, Jemal A. Cancer statistics, 2012. CA Cancer J Clin 2012;62:10-29.

2. Jung KW, Won YJ, Kong HJ, Oh CM, Seo HG, Lee JS. Cancer statistics in Korea: incidence, mortality, survival and prevalence in 2010. Cancer Res Treat 2013;45:1-14.

3. Hamilton W, Round A, Sharp D, Peters TJ. Clinical features of colorectal cancer before diagnosis: a population-based case-control study. Br J Cancer 2005;93:399-405.

4. Roberts MC, Millikan RC, Galanko JA, Martin C, Sandler RS. Constipation, laxative use, and colon cancer in a North Carolina population. Am J Gastroenterol 2003;98:857-64.

5. Watanabe T, Nakaya N, Kurashima K, Kuriyama S, Tsubono Y, Tsuji I. Constipation, laxative use and risk of colorectal cancer: The Miyagi Cohort Study. Eur J Cancer 2004;40:2109-15.

6. Power AM, Talley NJ, Ford AC. Association between constipation and colorectal cancer: systematic review and meta-analysis of observational studies. Am J Gastroenterol 2013;108:894-903.

7. Stapley S, Peters TJ, Sharp D, Hamilton W. The mortality of colorectal cancer in relation to the initial symptom at presentation to primary care and to the duration of symptoms: a cohort study using medical records. Br J Cancer 2006;95:1321-5.

8. Chen HM, Weng YR, Jiang B, Sheng JQ, Zheng P, Yu CG, et al. Epidemiological study of colorectal adenoma and cancer in symptomatic patients in China between 1990 and 2009. J Dig Dis 2011;12:371-8.

9. John SK, George S, Primrose JN, Fozard JB. Symptoms and signs in patients with colorectal cancer. Colorectal Dis 2011;13:17-25.

10. Alexiusdottir KK, Moller PH, Snaebjornsson P, Jonasson L, Olafsdottir EJ, Bjornsson ES, et al. Association of symptoms of colon cancer patients with tumor location and TNM tumor stage. Scand J Gastroenterol 2012;47:795-801.

11. Katoh H, Yamashita K, Wang G, Sato T, Nakamura T, Watanabe M. Prognostic significance of preoperative bowel obstruction in stage III colorectal cancer. Ann Surg Oncol 2011;18:2432-41.

12. Lee GY, Lee SM, Jang JH, Oh HK, Kim DW, Ahn S, et al. Preoperative constipation is associated with poor prognosis of rectal cancer: a prospective cohort study. J Korean Surg Soc 2013;85:35-42. 
Appendix. Medical institutes (listed by alphabetical order)

Asan Medical Center, University of Ulsan College of Medicine, Seoul, Korea

Chosun University School of Medicine, Gwangju, Korea

Chungnam National University Hospital, Daejeon, Korea

Eulji General Hospital, Seoul, Korea

Gachon University Gil Medical Center, Gachon University of Medicine and Science, Incheon, Korea

Hallym University Sacred Heart Hospital, Hallym University College of Medicine, Anyang, Korea

Incheon St. Mary's Hospital, The Catholic University of Korea College of Medicine, Incheon, Korea

Inha University School of Medicine, Incheon, Korea

Inje University Sanggye Paik Hospital, Inje University College of Medicine, Seoul, Korea

Konkuk University Medical Center, Konkuk University School of Medicine, Seoul, Korea

Konyang University College of Medicine, Daejeon, Korea

Korea Cancer Center Hospital, Korea Institute of Radiological \& Medical Sciences, Seoul, Korea

Korea University College of Medicine, Seoul, Korea

National Cancer Center, Goyang, Korea

Samsung Medical Center, Sungkyunkwan University School of Medicine, Seoul, Korea

Seoul National University Bundang Hospital, Seoul National University College of Medicine, Seongnam, Korea

Seoul National University College of Medicine, Seoul, Korea

Seoul St. Mary's Hospital, The Catholic University of Korea College of Medicine, Seoul, Korea

Soonchunhyang University Bucheon Hospital, Soonchunhyang University College of Medicine, Bucheon, Korea

Soonchunhyang University College of Medicine, Cheonan, Korea

Yang Hospital, Seoul, Korea

Yonsei University College of Medicine, Seoul, Korea

Yonsei University Health System, Yonsei University College of Medicine, Seoul, Korea

Yonsei University Wonju College of Medicine, Wonju, Korea 